\title{
Heparinized cardiopulmonary bypass circuits and low systemic anticoagulation: An analysis of nearly 6000 patients undergoing coronary artery bypass grafting
}

\author{
Eivind Øvrum, MD, PhD, Geir Tangen, MD, Stein Tølløfsrud, MD, PhD, Bjørn Skeie, MD, PhD, \\ Mari Anne L. Ringdal, CCP, Reidar Istad, CCP, and Rolf Øystese, CCP
}

\begin{abstract}
Objective: Heparin coating of cardiopulmonary bypass circuits reduces the inflammatory response and increases the thromboresistance during extracorporeal circulation. These properties enables a lower systemic heparin dose, which has been shown to reduce the need for blood transfusions. Experience with this technique accumulated over 11 years has been analyzed.
\end{abstract}

\begin{abstract}
Methods: All patients underwent on-pump coronary artery bypass grafting with heparin-coated circuits. Apart from some patients receiving a high intraoperative dose of aprotinin, the systemic heparin dose was reduced, with a lower level of an activated clotting time of 250 seconds during extracorporeal circulation. The overall strategy aimed at a fast-track regimen, with early extubation, minimal use of blood transfusions, and rapid postoperative recovery.

Results: Altogether, 5954 patients were included; 1131 (19.0\%) were female (median age, 70 years), and 4823 were male (median age, 65 years). The median additive EuroSCORE was 3 (range, $0-14$; mean $3.5 \pm 2.5$ ). No significant signs of clotting were seen in any part of the extracorporeal circuit. Bank blood products were given to $427(7.2 \%)$ patients. Median extubation time was 1.7 hours. The stroke rate was $1.0 \%$, transient neurologic deficits occurred in $0.7 \%$, and perioperative myocardial infarction occurred in $1.2 \%$. On the fifth day, $88.1 \%$ of the patients were physically rehabilitated and ready for discharge. Thirty-day mortality was $0.9 \%$ (54 patients).
\end{abstract}

Conclusions: The experience with this patient cohort including mostly low- to medium-risk patients with a relatively short cardiopulmonary bypass time indicates that coronary artery bypass grafting performed with heparincoated circuits and reduced level of systemic heparinization is safe and results in a very satisfactory clinical course. No signs of clotting or other technical incidents were recorded. (J Thorac Cardiovasc Surg 2011;141:1145-9)

\begin{abstract}
Modern cardiac surgery has gained a high level of quality over the years. Particularly for coronary artery bypass surgery, the accumulated experience with a large number of procedures performed every year has resulted in improved results, despite the increasing number of elderly and highrisk patients. ${ }^{1}$ The low mortality rate is likely due to a continuous improvement in technical skill, simplified procedures, improvements in myocardial protection, better anesthesia and intensive care, and better techniques and equipment for extracorporeal circulation. On this background, it might be difficult, even impossible, to prove the effects of a single step or a single procedure to be superior over those of another. However, analyzing the experience obtained through a substantial number of patients treated similarly over many years might provide some information of clinical relevance.

\footnotetext{
From the Oslo Heart Center, Division of Cardiovascular and Respiratory Medicine and Surgery, Oslo University Hospital, Rikshospitalet, Oslo, Norway.

Disclosures: Authors have nothing to disclose with regard to commercial support.

Received for publication April 26, 2010; revisions received June 24, 2010; accepted

for publication July 7, 2010; available ahead of print Aug 16, 2010.

Address for reprints: Eivind Øvrum, MD, PhD, Thorakskirurgisk avdeling, avd.

Akersbakken, Box 2684 St. Hanshaugen, 0131 Oslo, Norway (E-mail: eivind. ovrum@hjertesenteret.no).

0022-5223/\$36.00

Copyright (c) 2011 by The American Association for Thoracic Surgery
}

doi:10.1016/j.jtcvs.2010.07.003
\end{abstract}

Heparin-coated cardiopulmonary bypass (CPB) circuits are known to reduce the inflammatory response during extracorporeal circulation. ${ }^{2-4}$ This modification of the artificial surfaces in contact with blood is also shown to increase thromboresistance, and the equipment enables a lower systemic heparin dose, which might lead to reduced bleeding and less blood transfusions. ${ }^{5-7}$ Encouraged by our initial experience more than a decade ago, ${ }^{8,9}$ the use of heparin-coated circuits and reduced systemic heparinization became routine in our department for patients undergoing first-time myocardial revascularization. The system was integrated in a fast-track regimen, aiming at rapid extubation and physical rehabilitation, as well as minimal use of blood transfusions. The objective of the present study was to evaluate the accumulated experience gained over a period of 11 years.

\section{MATERIALS AND METHODS \\ Patients' Characteristics}

From January 1, 1998, until December 2008, 6478 consecutive patients underwent myocardial revascularization with heparin-coated CPB circuits in our department. Patients who had undergone previous cardiac surgery $(\mathrm{n}=98)$ and patients receiving a high intraoperative dose of aprotinin $(n=426)$ were given a full dose of heparin and were excluded from the present study. This left 5954 patients available for the analysis. Approximately 


\section{Abbreviations and Acronyms}

$\mathrm{ACT}=$ activated clotting time

$\mathrm{CABG}=$ coronary artery bypass grafting

$\mathrm{CPB}=$ cardiopulmonary bypass
$80 \%$ of the patients had elective operations. Some patient categories were taken care of by a neighboring university department, such as patients with severe renal dysfunction, patients in need of a combined carotid and coronary operation, and those requiring operations for left ventricular aneurysm. The subjects are consequently somewhat selected, which should be taken into consideration when evaluating the results. Otherwise, a typical coronary artery bypass patient population was treated (Table 1 ).

\section{Anesthesia}

The anesthesia protocol was designed to permit early extubation and included a combination of diazepam $(0-0.2 \mathrm{mg} / \mathrm{kg})$, midazolam hydrochloride $(0-0.2 \mathrm{mg} / \mathrm{kg})$, low-dose fentanyl $(4-8 \mu \mathrm{g} / \mathrm{kg})$, and pancuronium bromide supplemented with isoflurane. An arterial and 2 central venous lines were the standard. Extended monitoring with pulmonary catheters or transesophageal echocardiography was rarely done and was restricted to cases of postoperative cardiopulmonary decompensation. If not particularly indicated, no chest radiographs were taken the day of the operation.

\section{Operation and CPB}

Standard operative procedures included median sternotomy and CPB with a 2-stage cannula in the right atrium and a cannula in the ascending aorta. The aorta was crossclamped while the distal anastomoses were completed. Myocardial protection consisted of intermittent antegrade administration of cold blood cardioplegic solution or crystalloid cardioplegic solution (St. Thomas' Hospital solution no. 2). Anastomosis between the in situ left internal thoracic artery and the left anterior descending artery, supplemented with saphenous vein grafts, was performed most often. The proximal vein anastomoses were constructed during partial occlusion of the ascending aorta while the patient was being rewarmed.

CPB was performed with either a Stöckert roller pump (PFC III; Stöckert Instrumente $\mathrm{GmbH}$, Munich, Germany) or a Maquet HL 30 roller pump (Maquet Cardiopulmonary AG, Hirrlingen, Germany) with a pulsatile flow control and at a flow rate of $2.4 \mathrm{~L} \cdot \mathrm{m}^{-2} \cdot \mathrm{min}^{-1}$. Standard adult sizes of the circuits were used and primed with $2000 \mathrm{~mL}$ of Ringer's acetate. Mild hypothermia (blood temperature, $32^{\circ} \mathrm{C}-34^{\circ} \mathrm{C}$ ) was instituted immediately after the start of bypass. During the first years of the study period, 2 heparin-coated systems were used: the Carmeda Bio-Active Surface (Medtronic, Inc, Minneapolis, Minn) system and the Duraflo II equipment (Baxter Healthcare Corp, Bentley Laboratories Division, Irvine, Calif). Because of changes in the manufacturer's situation, only the Carmeda system has been used since 2003 ( $73 \%$ of all patients).

A reduced dose of heparin (Nyco Pharma, Oslo, Norway), $150 \mathrm{IU} / \mathrm{kg}$, was administered for systemic anticoagulation. The activated clotting time (ACT; HemoTec, Englewood, Colo) had to exceed 250 seconds before $\mathrm{CPB}$ was started, and supplemental doses were administered, if necessary, to maintain this target ACT. ACT was repeatedly determined during $\mathrm{CPB}$, after protamine administration, and 2 hours postoperatively. For neutralization of heparin, a bolus dose of protamine (protamine sulfate; Novo Nordisk, Baksvard, Denmark), $1.3 \mathrm{mg} / 100 \mathrm{IU}$ heparin, was administered. The cannulas were removed before reversal of anticoagulation. Each circuit was examined visually for evidence of clots or fibrin formation after the operation. An additional protamine dose was considered if postoperative bleeding was greater than 1.5 to $2 \mathrm{~mL} / \mathrm{kg}$ body weight during the first 2 postoperative hours.
TABLE 1. Demographic data of 5954 patients undergoing consecutive coronary artery bypass

\begin{tabular}{lc}
\hline \multicolumn{1}{c}{ Clinical variable } & Median (range) \\
\hline Male patients ( $\mathrm{n}=4823$ ), age $(\mathrm{y})$ & $65(31-89)$ \\
Female patients ( $\mathrm{n}=1131[19.5 \%]$ ), age $(\mathrm{y})$ & $70(27-89)$ \\
NYHA class III-IV (\% of patients) & 56.5 \\
Urgent/emergency operation (\% of patients) & 19.2 \\
Diabetes mellitus (\% of patients) & 17.2 \\
Left main stenosis (\% of patients) & 27.8 \\
Preoperative myocardial infarction (\% of patients) & 48.2 \\
Ejection fraction & $0.66(0.15-0.95)$ \\
Ejection fraction $<0.50$ (\% of patients) & 17.0 \\
EuroSCORE & $3(0-14)$ \\
\hline$N Y H A$, New York Heart Association.
\end{tabular}

\section{Blood Salvage}

The blood conservation protocol of the institution, previously described in detail, ${ }^{10}$ was applied to all patients. The main steps included removal of autologous blood before bypass for retransfusion after bypass (if the patient's preoperative hemoglobin concentration was adequate, usually $>120 \mathrm{~g} / \mathrm{L}$ ), routine use of cardiotomy suction, intraoperative and postoperative retransfusion of the oxygenator and circuit contents (without cell processing), and postoperative autotransfusion of shed mediastinal blood up to 18 hours postoperatively. The amount of postoperative bleeding from the time of sternal closure until the drains were removed was recorded. Normovolemic anemia was accepted to a hematocrit level of 0.25 postoperatively; a level less than this was considered an indication for allogeneic red blood cell transfusion.

\section{RESULTS Patients}

Demographic data are listed in Table 1. The female proportion was $19.0 \%$. Most patients were in New York Heart Association class III, and $11.1 \%$ of patients were in New York Heart Association class IV. The number of urgent or emergency operations was $1140(19.2 \%)$. The median additive EuroSCORE was 3 (range, $0-14$; mean, $3.5 \pm 2.5$ ).

\section{Operation and CPB}

The ACT before starting bypass was a median of 289 seconds (range, 225-900 seconds), and after 10, 30, and 50 minutes, the median ACT was 298 seconds (range, 179925 seconds), 281 seconds (range, 166-741 seconds), and 276 seconds (range, 182-740 seconds), respectively. The patients received a median of 4 (range, 1-9; mean $4.3 \pm$ 1.2) distal anastomoses. At least 1 internal thoracic artery anastomosis was constructed in nearly all patients $(99.7 \%)$. The median aortic crossclamp time was 33 minutes (range, 6-105 minutes), and pump time was 53 minutes (range, 11-165 minutes). There were no technical complications related to $\mathrm{CPB}$, and no grossly visible clots were observed in the circuits.

\section{Postoperative Course}

The patients were weaned from the ventilator a median of 1.7 hours (range, 0-700 hours) postoperatively (Table 2). 
TABLE 2. Postoperative course in 5954 patients undergoing coronary artery bypass

\begin{tabular}{lc}
\hline \multicolumn{1}{c}{ Variable } & No. $(\%)$ \\
\hline Ventilatory support postoperatively (h), median (range) & $1.7(0-700)$ \\
New episodes of atrial fibrillation (no. of patients) & $1688(30.1)$ \\
Postoperative myocardial infarction & $71(1.2)$ \\
Intra-aortic balloon pump & $11(0.2)$ \\
Stroke & $58(1.0)$ \\
Transient neurologic disturbances & $41(0.7)$ \\
Mediastinitis & $38(0.6)$ \\
30-d Mortality & $54(0.9)$ \\
\hline
\end{tabular}

Within 5 hours, $98.8 \%$ of the patients were extubated. One hundred twenty-six $(2.1 \%)$ patients underwent reexploration for postoperative bleeding. The threshold for re-exploration was low (mediastinal drainage $>250 \mathrm{~mL} / \mathrm{h}$ for 2 hours) to avoid transfusions of allogeneic blood products. Eleven $(0.2 \%)$ patients were assisted by an intra-aortic balloon pump postoperatively. Seventy-five $(1.3 \%)$ patients received inotropic drug therapy for more than 30 minutes after the operation. Episodes of atrial fibrillation in patients with preoperative sinus rhythm were encountered in $30.1 \%$. Considering the low systemic heparinization, there were no clinical indications of increased risk for thromboembolic complications. The incidences of both neurologic events and perioperative myocardial infarction were low (Table 2). The diagnosis of stroke or transient neurologic disturbances was done by a consultant neurologist. In most cases a computed tomographic scan was performed, and the diagnosis was prospectively stored in the database. On the fifth postoperative day, $88.1 \%$ of the patients were able to walk stairs or ambulate outside the hospital. The 30 - day mortality was $0.9 \%$ (54 patients).

\section{Blood Salvage}

More than $80 \%$ of the patients had a preoperative hemoglobin concentration high enough to allow prebypass autologous blood removal (Table 3). The blood was returned to the patients after termination of CPB. Most of the mediastinal shed blood was autotransfused until the morning after the operation. Altogether, $425(7.2 \%)$ patients were given banked blood or blood products, leaving $5529(92.8 \%)$ patients to be discharged from the hospital without being exposed to allogeneic blood products. The decrease in hemoglobin concentration after the operation was $26 \mathrm{~g} / \mathrm{L}$ (Table 3).

\section{DISCUSSION}

The present data indicate that the routine use of heparincoated CPB circuits combined with reduced systemic heparinization is safe and has encouraging clinical results, with low rates of morbidity and mortality. The requirement for banked blood transfusions was modest. No clotting forma-
TABLE 3. Blood conservation in $\mathbf{5 9 5 4}$ patients undergoing coronary artery bypass

\begin{tabular}{lc}
\hline \multicolumn{1}{c}{ Variable } & Median (range) \\
\hline Prebypass autologous removal $(\mathrm{mL}), \mathrm{n}=4865$ & $1040(100-3100)$ \\
Mediastinal drainage $(\mathrm{mL})$ & $640(120-7355)$ \\
Postoperative autotransfusion $(\mathrm{mL}), \mathrm{n}=5927$ & $600(120-3735)$ \\
Resternotomy for bleeding (patients) & $126(2.1 \%)$ \\
Patients receiving blood products $(\geq 1$ component) & $425(7.2 \%)$ \\
$\quad$ Red blood cells & 362 \\
Fresh frozen plasma & 130 \\
Platelets & 82 \\
Platelets preoperatively $\left(\times 10^{3}\right)$ & $231(68-999)$ \\
Platelets at discharge $\left(\times 10^{3}\right)$ & $238(28-873)$ \\
Hemoglobin concentration preoperatively $(\mathrm{g} / \mathrm{L})$ & $144(83-197)$ \\
Hemoglobin concentration at discharge $(\mathrm{g} / \mathrm{L})$ & $118(75-165)$ \\
\hline
\end{tabular}

tions or other technical problems were encountered, and the incidences of thromboembolic events were within expected ranges for this patient group.

To our knowledge, this is by far the largest consecutive series of patients undergoing coronary artery bypass grafting (CABG) with heparin-coated CPB equipment. The experience accumulated over more than a decade might provide relevant clinical information, although no evidence of being superior to other treatment modalities can be demonstrated. Ranucci and colleagues ${ }^{11}$ recently performed a metaanalysis of 4360 patients retrieved from 36 controlled randomized series, comparing biocompatible circuits with uncoated controls. Only 6 series had more than 100 patients in each arm. Patients treated with biocompatible circuits had a lower rate of red cell transfusions and atrial fibrillation and shorter durations of stay in the intensive care unit. The blood-saving effect of reducing systemic anticoagulation could not be evaluated from this analysis, but other clinical reports have indicated less postoperative bleeding and reduced banked blood requirements when decreasing the amount of systemic heparin. ${ }^{5,6}$ In a prospective randomized series of 203 patients undergoing CABG, the total amount of mediastinal drainage was significantly less in the patients undergoing CPB with heparin-coated circuits and a low heparin dose compared with those patients treated with uncoated but otherwise identical circuits and full systemic anticoagulation. ${ }^{7}$

Concern has been raised regarding increased thrombogenicity when the level of systemic heparinization is reduced during CPB with heparin-coated circuits. ${ }^{12}$ In previous randomized studies we were not able to demonstrate any evidence of increased thrombin formation, fibrinolytic activity, or consumption of coagulation factors. ${ }^{7,13}$ These studies were performed under similar clinical conditions as in the present material, with low- to medium-risk patients undergoing $\mathrm{CABG}$ and a relatively short $\mathrm{CPB}$ time. The clinical correlate of modest postoperative bleeding indicates adequate anticoagulation and the absence of hyperfibrinolysis. Similar 
findings were seen in patients at higher risk and longer $\mathrm{CPB}$ times, with no indications of increased thrombogenicity. ${ }^{14}$

Heparin-coated circuits attenuate the inflammatory response to CPB and have been shown to preserve organ function during and after surgical intervention..$^{2-4}$ In a large multicenter study of patients at higher risk, ${ }^{15}$ heparincoated circuits were associated with a shorter intensive care unit and postoperative hospital stay and had a protective effect on lung and kidney function. Other studies have indicated that heparinized circuits reduce the cognitive dysfunction after $\mathrm{CPB} .{ }^{16}$ These findings of improved organ function might have had an effect on the rapid and uneventful postoperative recovery seen in most of our patients. Also, the positive influence on postoperative hemostasis might improve the clinical course. As an integrated part of our blood conservation protocol, the use of heparin-coated circuits and low systemic anticoagulation resulted in a transfusion rate of less than $8 \%$. Transfusion of allogeneic blood and blood products is known to carry several complications, ${ }^{17}$ and we assume that the absence of transfusion-related morbidity also was an important factor for the uneventful rehabilitation after the operation.

Early tracheal extubation is another important step to initiate a fast postoperative recovery and might reduce the need for conventional intensive care to a small number of patients. ${ }^{18}$ Early extubation improves postextubation intrapulmonary shunt fraction ${ }^{19}$ and can prevent oversedation and resultant depression of the respiratory center, which prolongs intensive care unit stay.

From a technical point of view, there were no events or problems related to the low systemic heparinization in the present series. However, in a previous study we experienced some clots in the cardiotomy reservoir after CPB in 2 redo patients. ${ }^{8}$ No detectable side effects were seen, but after that time, we used a full heparin dose in this subgroup of patients. A minor portion of the patients receiving a high intraoperative dose of aprotinin were also given a full dose of heparin because of studies indicating increased thrombin formation in combination with reduced anticoagulation. ${ }^{20}$ Other authors ${ }^{21}$ have also recommended a full heparin dose in valve operations, and therefore reduced heparinization should be restricted to first-time CABG.

The use of heparin-coated circuits is certainly not the major reason for the good clinical results but is an important part of a philosophy to reduce the deleterious effects of $\mathrm{CPB}$ and to minimize blood transfusions. The ultimate approach would be to perform coronary surgery without a heartlung machine. However, we have chosen to do the revascularization on pump in all patients, taking advantage of performing an optimal number of anastomoses on an arrested heart. A recent multicenter report ${ }^{22}$ confirmed previous studies that off-pump CABG resulted in fewer grafts, and after 1 year, the patients had worse outcomes and a poorer patency rate than the on-pump patients. In the present series the mean number of distal anastomoses was 4.3, ranging from 1 to 9 , indicating a high rate of complete revascularization.

In this context other technical aspects should also be in focus, such as duration of $\mathrm{CPB}$ and ischemic arrest. Activation of blood cells and the coagulation, fibrinolytic, and complement systems increase with time on bypass. ${ }^{13}$ It has also been demonstrated that $\mathrm{CPB}$ time is a determinant for prolonged mechanical ventilation after $\mathrm{CABG} .{ }^{23}$ With regard to the ischemic stress imposed on the myocardium, studies have shown that the duration of ischemic time is an independent risk factor for the development of postoperative myocardial infarction, starting relatively early after aortic crossclamping. ${ }^{24}$ Therefore efforts should be made to plan surgical procedures in a way that reduces the ischemic and pump times to a minimum. However, this approach should not compromise the aim of complete revascularization, which is known to have a significant effect on long-term morbidity and survival. ${ }^{25}$

In summary, the evaluation of this large patient cohort including mostly low- to medium-risk patients with a relatively short CPB time indicates that CABG performed with heparin-coated circuits and reduced level of systemic heparinization is safe and results in a very satisfactory clinical course. There were few postoperative complications, limited need for banked blood transfusions, and short periods of postoperative ventilatory support. The mortality was low, and the patients were physically rehabilitated after a few days.

\section{References}

1. Song HK, Diggs BS, Slater MS, Guyton SW, Ungerleider RM, Welke KF. Improved quality and cost-effectiveness of coronary artery bypass grafting in United States from 1988 to 2005. J Thorac Cardiovasc Surg. 2009;137:65-9.

2. Videm V, Svennevig JL, Fosse E, Semb G, Østerud A, Mollnes TE. Reduced complement activation with heparin-coated oxygenator and tubings in coronary bypass operations. J Thorac Cardiovasc Surg. 1992;103:806-13.

3. Gu YJ, van Oeveren W, Akkerman C, Boonstra PW, Huyzen RJ, Wildevuur CR. Heparin-coated circuits reduce the inflammatory response to cardiopulmonary bypass. Ann Thorac Surg. 1993;55:917-22.

4. Fosse E, Moen O, Johnson E, Semb G, Brockmeier V, Mollnes TE, et al. Reduced complement and granulocyte activation with heparin coated cardiopulmonary bypass. Ann Thorac Surg. 1994;58:472-7.

5. Von Segesser LK, Weiss BM, Pasic M, Garcia E, Turina MI. Risk and benefit of low systemic heparinization during open heart operations. Ann Thorac Surg. 1994;58:391-8

6. Aldea GS, Doursounian BA, O'Gara P, Treanor P, Shapira OM, Lazar HL, et al. Heparin-bonded circuits with a reduced anticoagulation protocol in primary CABG: a prospective, randomized study. Ann Thorac Surg. 1996;62:410-8.

7. Øvrum E, Åm Holen E, Tangen G, Brosstad F, Abdelnoor M, Ringdal MAL, et al. Completely heparinized cardiopulmonary bypass and reduced systemic heparin: clinical and hemostatic effects. Ann Thorac Surg. 1995;60:365-71.

8. Øvrum E, Tangen G, Øystese R, Ringdal MAL, Istad R. Comparison of two heparin-coated extracorporeal circuits with reduced systemic anticoagulation in routine coronary artery bypass surgery. J Thorac Cardiovasc Surg. 2001;121: 324-30.

9. Øvrum E, Tangen G, Tølløfsrud S, Ringdal MAL. Heparin-coated circuits and reduced systemic anticoagulation applied to 2500 consecutive first-time coronary artery bypass grafting procedures. Ann Thorac Surg. 2003;76:1144-8.

10. Øvrum E, Åm Holen E, Tangen G. Consistent non-pharmacologic blood conservation in primary and reoperative coronary artery bypass grafting. Eur J Cardiothorac Surg. 1995;9:30-5. 
11. Ranucci M, Balduini A, Ditta A, Boncilli A, Brozzi S. A systematic review of biocompatible cardiopulmonary bypass circuits and clinical outcome. Ann Thorac Surg. 2009;87:1311-9.

12. Edmunds LH Jr. Surface-bond heparin—panacea or peril? Ann Thorac Surg. 1994;58:285-6.

13. Øvrum E, Brosstad F, Åm Holen E, Tangen G, Abdelnoor M. Effects on coagulation and fibrinolysis with reduced versus full systemic heparinization and heparin-coated cardiopulmonary bypass. Circulation. 1995;92: 2579-84.

14. Aldea GS, O'Gara P, Shapira OM, Treanor T, Osman A, Patalis E, et al. Effect of anticoagulation protocol on outcome in patients undergoing CABG with heparin-bonded cardiopulmonary bypass circuits. Ann Thorac Surg. 1998;65: 425-33.

15. Ranucci M, Mazzucco A, Pessotto R, Grillone G, Casati V, Porreca L, et al. Heparin-coated circuits for high-risk patients: a multicenter, prospective, randomized trial. Ann Thorac Surg. 1999;67:994-1000.

16. Heyer EJ, Lee KS, Manspeizer HE, Mongero L, Spanier TB, Caliste X, et al. Heparin-bonded cardiopulmonary bypass circuits reduce cognitive dysfunction. $J$ Cardiothorac Vasc Anesth. 2002;16:37-42.

17. Slater NG. Autologous blood transfusion today. Br J Clin Pract. 1992;46:193-7.

18. Westaby S, Pillai R, Parry A, O'Regan D, Giannopoulos N, Grebenik K, et al. Does modern cardiac surgery require conventional intensive care? Eur J Cardiothorac Surg. 1993;7:313-8.
19. Cheng DCH, Karski J, Peniston C, Asokumar B, Raveendran G, Carroll J, et al Morbidity outcome in early versus conventional tracheal extubation after coronary artery bypass grafting: a prospective randomized controlled trial. $J$ Thorac Cardiovasc Surg. 1996;112:755-64.

20. Kipfer B, Engelberger L, Gygax E, Nydegger U, Carrel T. Is reduced systemic heparinization justified with heparin-bonded bypass circuits in cardiac surgery? Experience with and without aprotinin. Transfus Apher Sci. 2003;29:17-24.

21. Shapira OM, Aldea GS, Zelingher J, Volpe J, Fitzgerald C, DeAndrade K, et al Enhanced blood conservation and improved clinical outcome after valve surgery using heparin-bonded cardiopulmonary bypass circuits. J Card Surg. 1996;11: 307-17.

22. Shroyer AL, Grover FL, Hattler B, Collins JF, McDonald GO, Kozora E, et al Veterans Affairs Randomized On/Off Bypass (ROOBY) Study Group. Onpump versus off-pump coronary-artery bypass surgery. N Engl J Med. 2009 361:1827-37.

23. Habib RH, Zachrias A, Engoren M. Determinants of prolonged mechanical ventilation after coronary artery bypass grafting. Ann Thorac Surg. 1996;62:1164-71.

24. Øvrum E, Abdelnoor M, Forfang K. Aortic crossclamping time and incidence of perioperative myocardial infarction after coronary artery bypass surgery. Asian Cardiovasc Thorac Ann. 1997;5:77-82.

25. Jones EL, Weintraub WS. The importance of completeness of revascularization during long-term follow-up after coronary artery operation. J Thorac Cardiovasc Surg. 1996;112:227-37. 